\title{
Intramural tracheal bronchogenic cyst: a case report
}

\author{
Go Ohba ${ }^{1 *}$, Miki Toma', Koji Komori ${ }^{1}$, Seiichi Hirobe ${ }^{1}$ and Ryuji Fukuzawa ${ }^{2}$
}

\begin{abstract}
Intramural bronchogenic cysts are extremely rare. We describe the case of an intramural bronchogenic cyst in a 2 year old boy who underwent tracheal resection and end-to-end anastomosis.
\end{abstract}

Keywords: Bronchogenic cyst; Intramural; End-to-end anastomosis

\section{Case report}

A 2 year old boy had suffered from inspiratory and expiratory wheezing since infancy, which was refractory to medications. Further examination with computed tomography (CT) revealed an unenhanced tracheal mass compressing the trachea on the left (Figure 1).

$\mathrm{He}$ was transferred to our institution for definitive treatment. On admission, chest radiography revealed apparent segmental narrowing of the mid-trachea, suggesting the existence of a paratracheal mass. The mass was of high intensity in the T2-weighted and isotense in the T1weighted images in magnetic resonance imaging (MRI) (Figure 2). Flexible bronchoscopy was performed indicating a smooth protrusion of antero-lateral wall of the trachea, and the tracheal lumen was severely occluded (Figure 3). These results suggested a probable diagnosis of bronchogenic cyst arising from outside the tracheal wall and compressing the tracheal lumen.

The operation was performed through a cervical transverse incision. The trachea was exposed and no mass was found in the paratracheal area. The anterior wall of mid-trachea was found to be bulging as the mass was within the tracheal wall. The bulging wall was thin, so that the contents could be seen through the wall. Mucous fluid spilled out when the wall was pinched. Because a bronchogenic cyst arising from the tracheal wall had not been expected, the possibility of malignant tumor could not be ruled out. A biopsy of the wall followed by definitive surgery was planned. Pathologically, the contents of

\footnotetext{
* Correspondence: gou.oba@tenshi.or.jp

${ }^{1}$ Department of Surgery, Tokyo Metropolitan Children's Medical Center,

Tokyo, Japan

Full list of author information is available at the end of the article
}

the wall were dense fibrous tissue, epithelial tissues and cartilaginous tissue. This result supported the diagnosis of an intramural bronchogenic cyst. Definitive surgery was performed a week after the previous operation. The affected tracheal segment was completely resected and an end-to-end anastomosis was performed to restore the trachea (Figure 4). The resected specimen proved to be a cystic lesion within the tracheal wall indicating an intramural bronchogenic cyst. The cyst wall was lined by respiratory epithelia and the wall contained cartilage (Figure 5). It was diagnosed as an intramural bronchogenic cyst.

The postoperative course was good and there is no recurrence one year after surgery.

\section{Discussion}

Bronchogenic cysts develop from abnormal budding of the tracheal diverticula during the embryological period. The exact time of these events has not been ascertained. Cysts are lined by epithelium, and their wall often contains mucous glands and cartilage.

Bronchogenic cysts can be classified into three categories in relation to the trachea as paratracheally, intraluminally, and intramurally. The localization of cysts between the mucosa and submucosa layer is called intraluminal and between the cartilages and adventitia is called intramural. In fact, the differentiation is complicated without pathological findings and cannot be distinguished before the operation (Stewart et al. 2002). Paratracheal cysts are found in various regions, depending on the level at which the abnormal budding occurred in the development of the tracheobronchial tree. Most cysts are found along the tracheobronchial tree, but have been reported to occur in various regions, such as neck, tongue, esophagus,

\section{Springer}




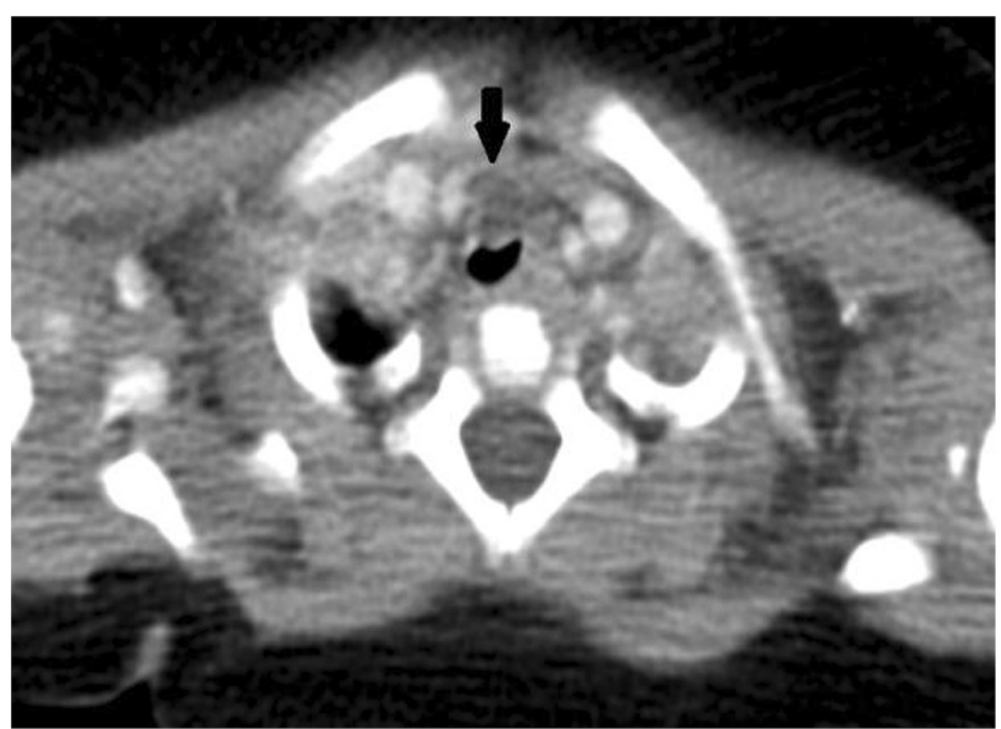

Figure 1 CT findings: a cystic mass compressing the anterior wall of the trachea (Arrow).

heart, retroperitoneum, and mesentery (Sauvat et al. 2006; Antoniou et al. 2012; Govaerts et al. 2012; Petrina et al. 2010).

Making preoperative diagnosis of bronchogenic cysts can be difficult. Chest radiographs are ineffective for accurate preoperative diagnosis, but the diagnosis can be made with $69.2 \%$ and $100 \%$ accuracy in CT scans and MRIs respectively (Kanemitsu et al. 1999). MRI proved very useful for making diagnosis, but there are some reports describing that the diagnosis of bronchogenic cysts was difficult even with MRI (Sauvat et al. 2006). Transtracheal endoscopic ultrasonography is reported to be useful in adults (Anantham et al. 2011), however, it has not been reported in children.
Intramural bronchogenic cysts are extremely rare and only two reports were found (Wenig and Abramson 1987; Klin et al. 1994). These reports also could not be diagnosed as intramural lesions prior to surgery. Diagnosis was usually performed by CT or MRI. The preoperative diagnosis was bronchogenic cyst in our case, and it was expected to be located beneath the anterior cervical muscles attaching to the tracheal wall. However, the trachea was exposed and the anterior wall of trachea was found to contain the cystic mass. The cyst was not expected to be intramural therefore the decision was made not to perform definitive surgery. The pathological diagnosis of bronchogenic cyst supported our plan for complete resection of the affected trachea.

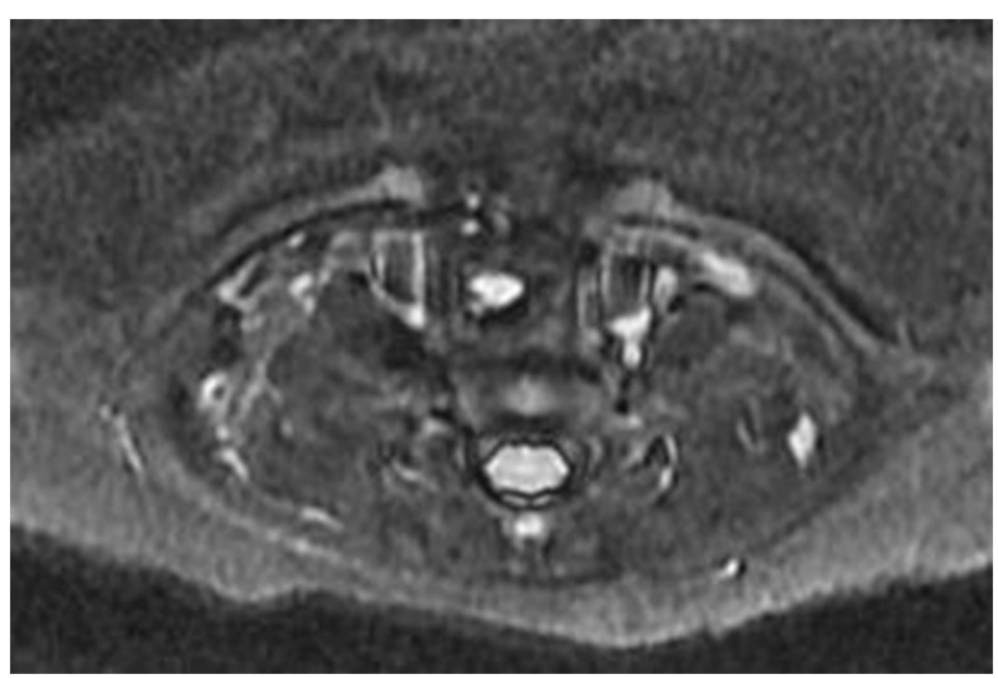

Figure 2 The mass was of high intensity in T2-weighted MRI images. 


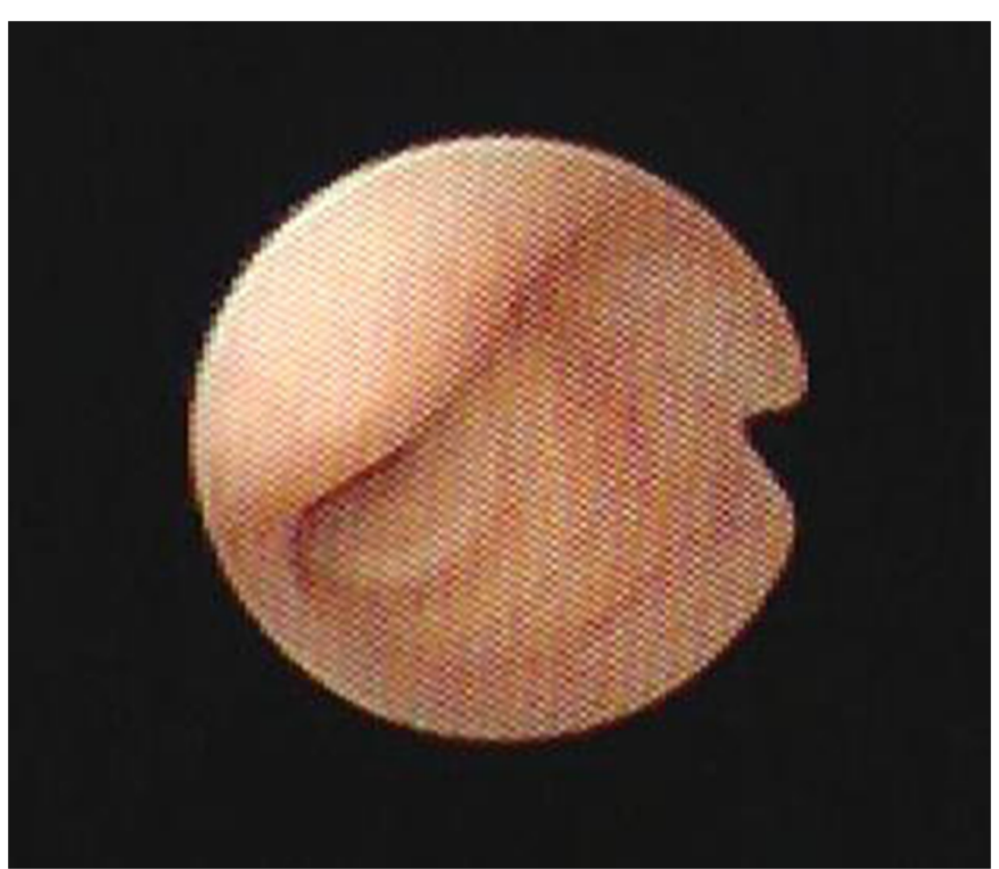

Figure 3 Bronchoscopy shows a smooth mass, causing stenosis of the trachea.

In this case, as the patient had developed respiratory symptoms since infancy, the surgical procedure was necessary. Treatment of asymptomatic bronchogenic cysts is controversial. But carcinoma arising from a bronchogenic cyst has been reported in an 8-year-old girl (Suen et al. 1993). Other symptoms, such as infection, bleeding and respiratory distress can develop, so the need for surgical excision in order to avoid those complications can be emphasized.

There was discussion as to whether complete resection of the affected tracheal rings was necessary or excision of the cyst followed by patch closure of the defect of

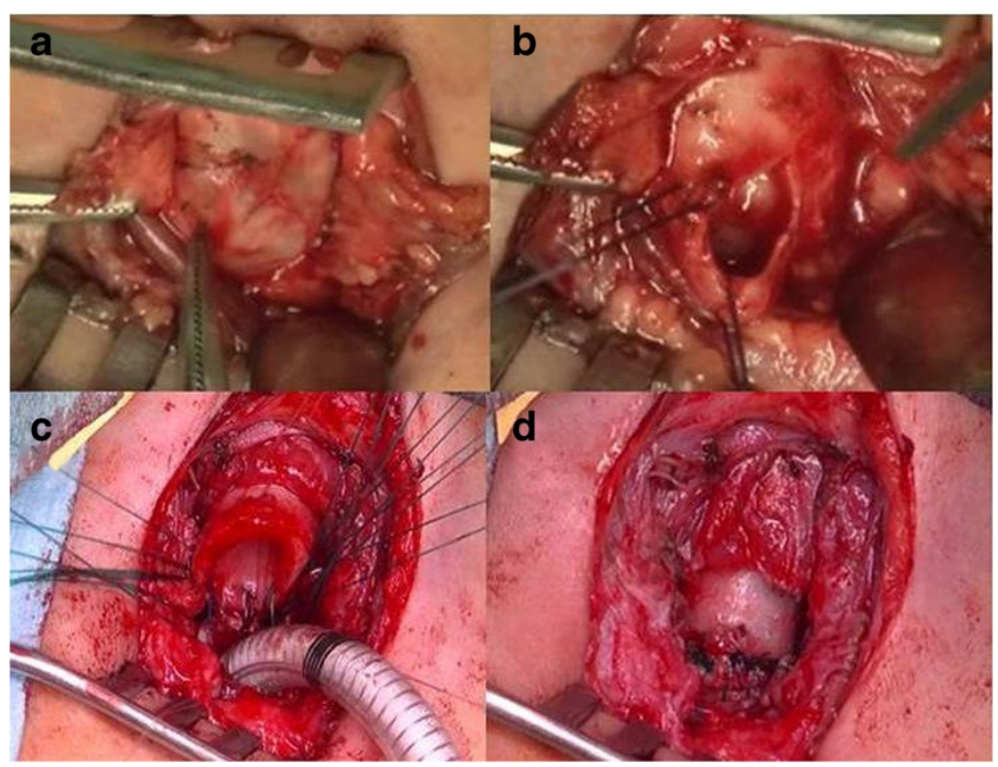

Figure 4 Interpretive findings (ab: first operation cd: second operation). a: The tracheal wall was bulging so that the mass was thought to be present intramurally. $\mathbf{b}$ : Mucus leaked when the wall was pinched and tracheal mucosa was exposed. c: Tracheal resection and end-to-end anastomosis was performed under operative field intubation. $\mathbf{d}$ : After end-to-end anastomosis. 


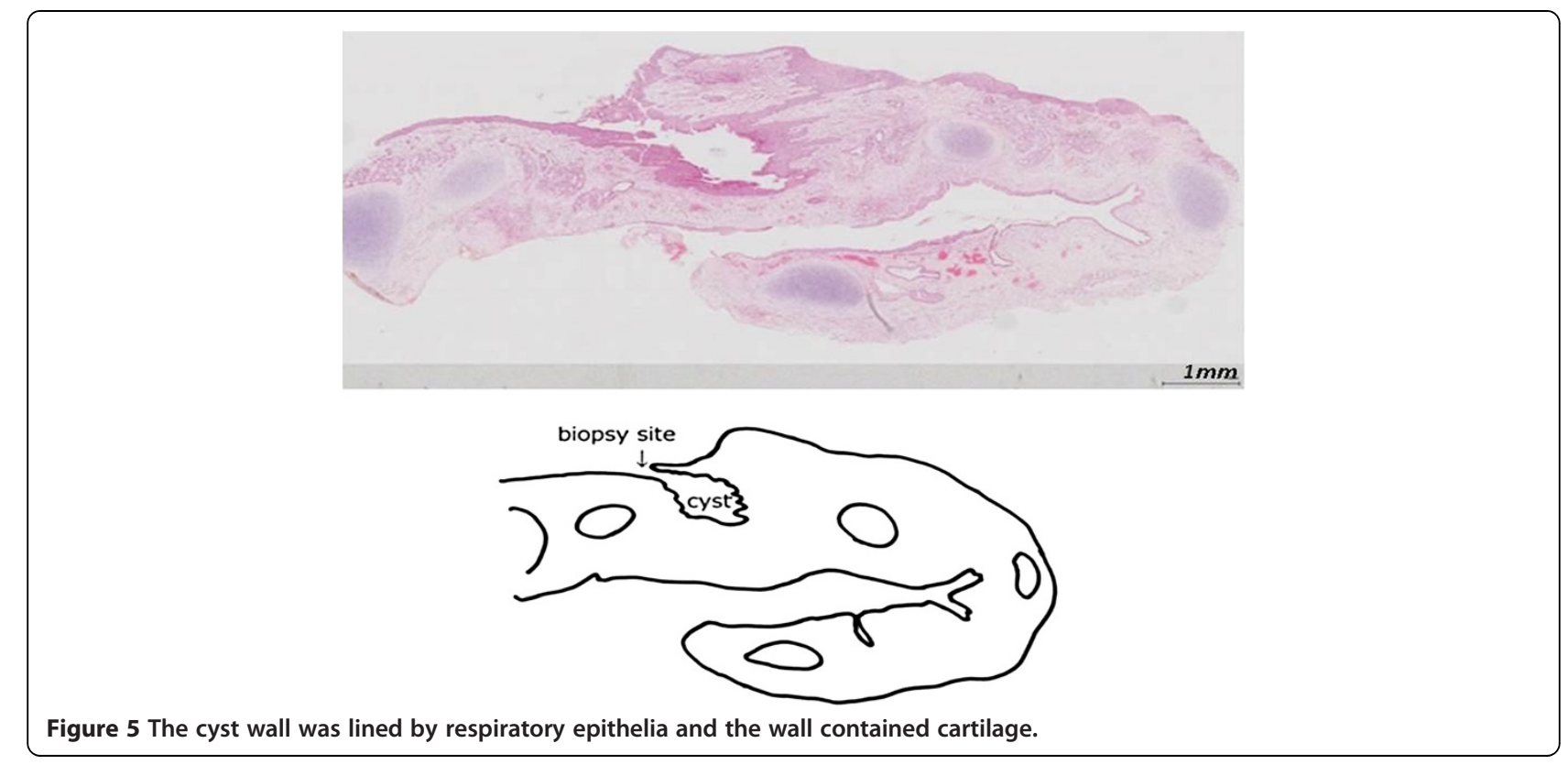

tracheal wall would be sufficient. Complete resection was chosen because the length of the affected tracheal rings was less than $2 \mathrm{~cm}$, end-to-end anastomosis of the trachea would be relatively safe without tension. Also, tracheomalacia might develop due to the defect of the anterior wall of the trachea in patch closure.

Excision of the cyst is apt to be conservative and complete excision is recommended. Recurrence 25 years after incomplete resection has been reported (Read et al. 1991). Although paratracheal cysts can be ablated from the tracheal wall, intramural cysts require tracheal wall resection for complete resection. Thoracoscopic laser excision or fenestration is sometimes useful, but the tracheal aventitia was too thin in this case therefore there was the risk of perforation. Drainage was also reported but long-term follow up is indicated to detect recurrence (Read et al. 1991; $\mathrm{Li}$ et al. 2010). Recently, CT-guided percutaneous treatment of bronchogenic cysts with needle aspiration and sclerotherapy was reported, but this technique was a small case series and further investigation is necessary ( $\mathrm{Li}$ et al. 2010). As a whole, we considered tracheal resection as safe and assured complete resection.

\section{Summary}

Intramural bronchogenic cysts are extremely rare and preoperative diagnosis is difficult. Intramural bronchogenic cysts should be considered when cystic tumors are close to the trachea, with tracheal resection and end-to-end anastomosis a safe surgical procedure for complete resection.

\section{Competing interests}

The authors declare that they have no competing interests.
Authors' contribution

All authors read and approved the final manuscript.

\section{Author details}

${ }^{1}$ Department of Surgery, Tokyo Metropolitan Children's Medical Center, Tokyo, Japan. ${ }^{2}$ Department of Pathology, Tokyo Metropolitan Children's Medical Center, Tokyo, Japan.

Received: 16 October 2013 Accepted: 12 May 2014 Published: 23 May 2014

\section{References}

Anantham D, Phua GC, Low SY, Koh MS (2011) Role of endobronchial ultrasound in the diagnosis of bronchogenic cysts. Diagn Ther Endosc 2011:468237

Antoniou A, Filias V, Mourtzis N, Economidou S, Schortsanitis P, Panagiotou M (2012) Intrapericardial bronchogenic cyst found incidentally during open heart surgery. Asian Cardiovasc Thorac Ann 20(6):737-738

Govaerts K, Van Eyken P, Verswijvel G, Van der Speeten K (2012) A bronchogenic cyst, presenting as a retroperitoneal cystic mass. Rare Tumors 4(1):e13

Kanemitsu Y, Nakayama H, Asamura H, Kondo H, Tsuchiya R, Naruke T (1999) Clinical features and management of bronchogenic cysts: report of 17 cases. Surg Today 29(11):1201-1205

Klin B, Springer C, Segal M, Eshel G, Tabachnik E, Vinograd I (1994) Recurrent cyanotic spells caused by a segmental intramural cyst of the upper trachea. Pediatr Pulmonol 18(2):119-121

Li L, Zeng XQ, Li YH (2010) CT-guided percutaneous large-needle aspiration and bleomycin sclerotherapy for bronchogenic cyst: report of four cases. J Vasc Interv Radiol 21(7):1045-1049

Petrina A, Boselli C, Cirocchi R, Covarelli P, Eugeni E, Badolato M, Finocchi L, Trastulli S, Noya G (2010) Bronchogenic cyst of the ileal mesentery: a case report and a review of literature. J Med Case Rep 4:313

Read CA, Moront M, Carangelo R, Holt RW, Richardson M (1991) Recurrent bronchogenic cyst. An argument for complete surgical excision. Arch Surg 126(10):1306-1308

Sauvat F, Fusaro F, Jaubert F, Galifer B, Revillon Y (2006) Paraesophageal bronchogenic cyst: first case reports in pediatric. Pediatr Surg Int 22(10):849-851 
Stewart B, Cochran A, Iglesia K, Speights VO, Ruff T (2002) Unusual case of stridor and wheeze in an infant: tracheal bronchogenic cyst. Pediatr Pulmonol 34(4):320-323

Suen HC, Mathisen DJ, Grillo HC, LeBlanc J, McLoud TC, Moncure AC, Hilgenberg AD (1993) Surgical management and radiological characteristics of bronchogenic cysts. Ann Thorac Surg 55(2):476-481

Wenig BL, Abramson AL (1987) Tracheal bronchogenic cyst: a new clinical entity? Ann Otol Rhinol Laryngol 96(1 Pt 1):58-60

doi:10.1186/2193-1801-3-262

Cite this article as: Ohba et al:: Intramural tracheal bronchogenic cyst: a case report. SpringerPlus 2014 3:262

Submit your manuscript to a SpringerOpen ${ }^{\circ}$ journal and benefit from:

- Convenient online submission

- Rigorous peer review

- Immediate publication on acceptance

- Open access: articles freely available online

- High visibility within the field

- Retaining the copyright to your article

Submit your next manuscript at $\boldsymbol{\nabla}$ springeropen.com 